\title{
The Prognostic Factors for Locally Advanced cervical Cancer Patients Treated by Cisplatin Based Concurrent Chemoradiotherpy- A Retrospective Study
}

\author{
S. Jeeva', V. Arun Ramanan², Sowmiya. KR ${ }^{3}$, P. Balasubramaniam ${ }^{4}$, Vidya ${ }^{5}$, Chandralekha ${ }^{6}$ \\ ${ }^{1}$ Associate Professor, Department of Radiation Oncology, Tamilnadu Government Multi Superspecialty Hospital, Chennai, ${ }^{2}$ Assistant Professor, Department of \\ Medical Oncology, Tamilnadu Government Multi Super specialty Hospital, Chennai, ${ }^{3}$ Professor, Department of community medicine, Chettinad Hospital and \\ research institute (CARE), Chennai, ${ }^{4}$ Professor, Department of Radiation Oncology, Tamilnadu Government Multi Superspecialty Hospital, Chennai, ${ }^{5}$ Assistant \\ Professor, Department of Radiation Oncology, Tamilnadu Government Multi Superspecialty Hospital, Chennai, ${ }^{6}$ Registrar, Department of Radiation Oncology, \\ Tamilnadu Government Multi Superspecialty Hospital, Chennai.
}

\section{Abstract}

Background: Aim: To identify the prognostic factors for the locally advanced cancer cervix patients treated with weekly cisplatin based concurrent chemoradiation. Subjects and Methods: We have analyzed 57 women with FIGO stage IB2-IIIB cervical cancer treated in the Oncology outpatient department of a tertiary care center between May 2014 to December 2016.Inclusion criteria includes patients treated with Radical Radiotherapy with cisplatin $30 \mathrm{mg} / \mathrm{m} 2$.Median total dose to point A was $72 \mathrm{~Gy}$. Data regarding age, performance status, stage, histology, grade, tumour size, pretreatment haemoglobin level, radiological imaging details, pelvic nodal involvement, compliance to treatment, no. of chemotherapy cycles, total duration of radiotherapy and toxicity profiles are reviewed from medical records. Primary endpoints were to assess the prognostic factors that affects the tumor response and progression free survival and disease free survival. Survival analysis was estimated using the Kaplan-Meier method and multivariate Cox proportional hazard model, to estimate the hazard ratio and $95 \%$ confidence intervals using IBM SPSS statistical software. Results: The median follow-up time was 18 months. The 2 year overall survival was $31.6 \%$ and PFS is $29.8 \%$. In univariate analysis presence of pelvic node, tumor size, radiotherapy treatment duration, no. of chemotherapy cycles were significantly associated with overall survival and progression free survival. In multivariate analysis, only tumour size and radiotherapy treatment duration significantly affected the overall survival and progression free survival. Conclusion: Bulky tumour and prolongation of treatment duration were poor prognostic factors for patients with locally advanced cervical cancer. Chemotherapy with a high cumulative dose of cisplatin tended to result in better survival.

Keywords: Locally advanced cervical cancer, concurrent chemoradiation, weekly ciplatin.prognostic factors

Corresponding Author: Dr. V. Arun Ramanan, Assistant Professor, Department of Medical Oncology, Tamilnadu Government Multi Super specialty Hospital, Chennai.

Received: February 2019

Accepted: February 2019

\section{Introduction}

Radiation is the main treatment modality for the locally advanced cancer cervix from FIGO stage IB2 to IVA. ${ }^{[1 \& 2]}$ Many studies proved that cisplatin based concurrent chemoradiation (CCRT)is superior in terms of local control and overall survival in locally advanced cervical cancer. ${ }^{[3 \& 4]}$ Hence toxicity profile is better with weekly cisplatin when compared to high dose cisplatin and has become the standard of care. ${ }^{[5]}$

As the outcome of locally advanced cancer cervix is moderate, despite of concurrent chemo radiation, it necessitates identifying the prognostic factors that may help us to further improve the survival. In this study we analyzed the prognostic factors for treatment response and survival in patients with locally advanced cancer cervix patients treated by cisplatin based CCRT.

\section{Subjects and Methods}

We have analyzed 57 patients with locally advanced cervical carcinoma. Inclusion criteria were non metastatic locally advanced cancer cervix patients who underwent CCRT with weekly cisplatin followed by high dose rate (HDR) brachytherapy boost, age < 60yrs, PS 0-2, with normal hematological and Biochemical parameters. The following data were collected from the medical records of the patients: Age, histopathology, grade, stage, tumour size, FIGO stage, pelvic nodal status, pretreatment haemoglobin value, total duration treatment, number of chemotherapy cycles and toxicity profiles. The clinical stage of the patients was assessed by clinical examination according to FIGO classification. Staging workup included the chest Xray, MRI abdomen and pelvis, sigmoidoscopy, cystoscopy whenever indicated. Baseline complete haemogram, liver function test, renal function tests were obtained and 
repeated before every cycle of chemotherapy, treatment.

\section{Radiation therapy}

All patients were treated with combination of External beam Radiotherapy (EBRT) and Intra cavitary brachytherapy. EBRT was delivered to whole pelvis by opposing AP/PA fields (2 field technique) by telecobalt machine. External radiation portals extended from L4 L5 junction to the mid obturator foramen or up to the introitus if the vagina was involved. Lateral borders were $1.5-2 \mathrm{~cm}$ lateral to the rim of the lesser pelvis. The total dose for pelvis was $50 \mathrm{~Gy}$ in 25 fractions over the period of 5 weeks after completion of EBRT, intracavitory brachytherapy was given as $8 \mathrm{~Gy}$ per fraction, 2 fractions in a gap period of one week by using 192Ir. the dose to point $\mathrm{A}$ in each fraction was $8 \mathrm{~Gy}$. If the dose to point B is not achieved, additional dose to parametrium by additional dose by EBRT to the lesion with rectal shields were given. The total dose to Point A combining EBRT with ICA was 70-75 Gy. The planned overall treatment time was less than 7-8 weeks.

\section{Chemotherapy}

The patients treated with weekly cisplatin received cisplatin $30 \mathrm{mg} / \mathrm{m}^{2}$ diluted in $250 \mathrm{ml}$ of $0.9 \%$ sodium chloride was administered over 1 hour .patients were hydrated adequately with $0.9 \%$ normal saline. 5HT3 antagonists and dexamethasone for antiemetic prophylaxis. Chemotherapy administration was withheld, if the total leukocyte count was less than $3500 \mathrm{~mm}^{3}$, platelet count less than 75,000 $\mathrm{mm}^{3}$, hemoglobin less than $9 \mathrm{gm} \%$ and serum creatinine more than $1.6 \mathrm{mg} / \mathrm{dl}$. No dose modifications were made.

\section{Evaluation of toxicity and response}

Patients were evaluated weekly for acute toxicities during treatment. And the toxicities were grade according to Common Terminology Criteria for Adverse Events (CTCAE) Version 4.02.. Clinical examination was done every month and by imaging every 6 months (CT/MRI abdomen and pelvis). Patients found to have pelvic recurrence were assessed for salvage surgeries like anterior/posterior/total pelvic exenteration depends on the extent of the tumour. The patients who could not be treated by surgery were treated with palliative chemotherapy. For response assessment, WHO criteria were used; complete response was defined as the disappearance of all gross lesions for 1 month after completion of radiotherapy and absence of new lesions. Partial response was defined as a > $50 \%$ reduction of tumor size for 1 months after completion of radiotherapy. Progressive disease was defined as the appearance of any new lesion during treatment or $>25 \%$ increase in size of local tumor. Stable disease (SD) if tumour response less than $50 \%$ and if progression less than $25 \%$. The responses were scored as complete response (CR), partial response (PR) and no response/progressive disease (NR/PD). CT/MRI abdomen \&pelvis was done after 6months and annually thereafter. After completion of treatment, patient's tumour response assessed by clinical examination at 6 weeks.

\section{Statistical analysis}

The endpoints were OS, progression-free survival (DFS). The OS was defined as the time from the initial date of CCRT, to the date of death from any cause or last followup. The PFS was calculatedfrom the initial date of CCRT, to the date of any evidence oflocal recurrence, or distant metastasis or last follow-up.Survival analysis was estimated using the Kaplan-Meier method. A univariate analysis for prognostic factors which affected the survival was performed using log rank test. Multivariate Cox proportionalhazard model was used to estimate the hazard ratio and $95 \%$ confidence intervals. The statistical analysis was performed using IBM-SPSS software, version 21.0. A p value $<0.05$ wasregarded as statistically significant.

\section{Results}

\begin{tabular}{|c|c|c|}
\hline Variables & & $\mathbf{N}(\%)$ \\
\hline \multirow[t]{2}{*}{ Age } & $<40$ years & $7 \quad(12.3)$ \\
\hline & $\geq 40$ & $50(87.7)$ \\
\hline \multirow[t]{2}{*}{ Histology } & SCC & $53 \quad(93)$ \\
\hline & Adeno & $4 \quad(7)$ \\
\hline \multirow[t]{5}{*}{ FIGO stage } & IB & $1 \quad(1.8)$ \\
\hline & II A & $\begin{array}{ll}1 & (1.8) \\
\end{array}$ \\
\hline & II B & $30 \quad(59.6)$ \\
\hline & III A & $1 \quad(1.8)$ \\
\hline & III B & $24(35.1)$ \\
\hline \multirow[t]{3}{*}{ Grade } & 1 & $24 \quad(42.1)$ \\
\hline & 2 & $26 \quad(45.6)$ \\
\hline & 3 & $\begin{array}{ll}7 & (12.3) \\
\end{array}$ \\
\hline \multirow[t]{2}{*}{ Cisplatin } & $<4$ & $\begin{array}{ll}13 & (22.8) \\
\end{array}$ \\
\hline & $\geq 4$ & $44 \quad(77.2)$ \\
\hline \multirow[t]{2}{*}{ Performance status } & 1 & $\begin{array}{ll}49 \quad(86) \\
\end{array}$ \\
\hline & 2 & $8 \quad(14)$ \\
\hline \multirow[t]{2}{*}{ Pre treatment $\mathrm{Hb}$} & $<11$ & $21 \quad(36.8)$ \\
\hline & $\geq 11$ & $\begin{array}{ll}36 & (63.2) \\
\end{array}$ \\
\hline \multirow[t]{2}{*}{ Pelvic node } & Involved & $13 \quad(22.8)$ \\
\hline & Not involved & $44 \quad(77.2)$ \\
\hline \multirow[t]{2}{*}{ RT duration } & $\leq 8$ weeks & $34 \quad(59.6)$ \\
\hline & $>8$ & $23 \quad(40.4)$ \\
\hline \multirow[t]{2}{*}{ Tumor size } & $<4$ & $23 \quad(40.4)$ \\
\hline & $\geq 4$ & $\begin{array}{ll}34 \quad(59.6) \\
\end{array}$ \\
\hline \multirow[t]{2}{*}{ Response at 6 weeks } & $\mathrm{CR}$ & $46 \quad(80.7)$ \\
\hline & PR & $11 \quad(19.3)$ \\
\hline
\end{tabular}

(RT-radiotherapy,CR-complete response, PR-partial response)

\section{Demographic data of patients}

The age of the patients in this study ranged from 32 to 69 years while the majority of patients was more than 40 years. According to FIGO staging $1.8 \%$ of patients had stage IB, $1.8 \%$ had IIA, $59.6 \%$ had IIB, $1.8 \%$ had IIIA and $24 \%$ had 35.1 IIIB. $22.8 \%$ of the patients diagnosed to have pelvic nodes radiologically. $77.2 \%$ of the patients received $\geq 4$ cycles of weekly cisplatin cycles and $22.8 \%$ of patients received $<4$ cycles of weekly cisplatin. Only $59.6 \%$ of the patients had completed the planned radiotherapy within $\leq 8$ weeks duration. Almost $80.7 \%$ of the patients achieved complete response at the end of the treatment and $19.3 \%$ had partial response. Only $35 \%$ of the patients had regular follow up and the rest were lost to follow up. The baseline characteristics of the study patients are shown in [Table 1]. 
Median follow up period of the study subjects is 18 months, ranging from 1 to 42 months. The 2 year overall survival was $31.6 \%$ and PFS is $29.8 \%$. The Kaplan meier curves for Overall survival(OS) and Progression free survival(PFS) were given in Fig1-4.In univariate analysis presence of pelvic nodes $(\mathrm{p}=0.05,0.031)$, tumor size $(\mathrm{p}=0.04,0.02)$, radiotherapy treatment duration $(\mathrm{p}=0.01,0.00)$, no of chemotherapy cycles $(0.045,0.05)$ were significantly associated with overall survival and progression free survival. In multivariate analysis only tumour size $(\mathrm{p}=0.04$, $0.02)$ and radiotherapy treatment duration $(\mathrm{p}=0.01,0.03)$ were significantly affecting the overall survival and progression free survival. The 2 year overall survival was $31.6 \%$ and PFS is 29.8\%. Thirteen patients $(22.8 \%)$ developed grade 1 and 2 GI toxicity and 33 patients $(57.89 \%)$ developed< grade 3 hematological toxicity. Seven patients $(12.3 \%)$ developed genitourinary system toxicity. Fourteen patients $(24.5 \%)$ developed local recurrence and $9(15.7 \%)$ had systemic recurrence. Also, delay in chemotherapy happened in $20 \%$ patients due to treatment toxicities. The results of univariate and multivariate analysis are shown in [Table 2,3].

\begin{tabular}{|c|c|c|c|}
\hline Variables & & OS\% & PFS\% \\
\hline \multirow[t]{3}{*}{ Age } & $<40$ years & 42.9 & 30 \\
\hline & $\geq 40$ & 30 & 28.6 \\
\hline & & $\mathrm{P}=0.063$ & $\mathrm{P}=0.037$ \\
\hline \multirow[t]{3}{*}{ Histology } & SCC & 25 & 25 \\
\hline & Adeno & 32.1 & 30.2 \\
\hline & & $\mathrm{P}=0.71$ & $\mathrm{P}=0.87$ \\
\hline \multirow[t]{6}{*}{ FIGO stage } & IB & 0 & 0 \\
\hline & II A & 0 & 0 \\
\hline & II B & 41.2 & 38.2 \\
\hline & III A & 0 & 0 \\
\hline & III B & 20 & 20 \\
\hline & & $\mathrm{P}=0.13$ & $\mathrm{P}=0.16$ \\
\hline \multirow[t]{4}{*}{ Grade } & 1 & 20.8 & 16.7 \\
\hline & 2 & 38.5 & 38.5 \\
\hline & 3 & 42.9 & 42.9 \\
\hline & & $\mathrm{P}=0.5$ & $\mathrm{P}=0.41$ \\
\hline \multirow[t]{3}{*}{ Cisplatin } & $<4$ & 30.8 & 30.8 \\
\hline & $\geq 4$ & 31.8 & 29.5 \\
\hline & & $\mathrm{P}=0.045$ & $\mathrm{P}=0.05$ \\
\hline \multirow[t]{3}{*}{ PS } & 1 & 32.7 & 30.6 \\
\hline & 2 & 25 & 25 \\
\hline & & $\mathrm{P}=0.77$ & $\mathrm{P}=0.98$ \\
\hline \multirow[t]{3}{*}{ Pre treatment $\mathrm{Hb}$} & $<11$ & 30.6 & 27.8 \\
\hline & $\geq 11$ & 33.3 & 33.3 \\
\hline & & $\mathrm{P}=0.8$ & $\mathrm{P}=0.85$ \\
\hline \multirow[t]{3}{*}{ Pelvic node } & Involved & 15.4 & 15.4 \\
\hline & Not involved & 36.4 & 34.1 \\
\hline & & $\mathrm{P}=0.05$ & $\mathrm{P}=0.031$ \\
\hline \multirow[t]{3}{*}{ RT duration } & $\leq 8$ weeks & 44.1 & 44.1 \\
\hline & $>8$ & 13 & 8.7 \\
\hline & & $\mathrm{P}=0.01$ & $\mathrm{P}=0.00$ \\
\hline \multirow[t]{3}{*}{ Tumor size } & $<4$ & 43.5 & 43.5 \\
\hline & $\geq 4$ & 23.5 & 20.6 \\
\hline & & $\mathrm{P}=0.04$ & $\mathrm{P}=0.02$ \\
\hline
\end{tabular}

(PS-performance status,RT-radiotherapy)
Table 3: prognostic factors for OS\&PFS: multivariate analysis

\begin{tabular}{|c|c|c|c|c|}
\hline OS & OS & $\begin{array}{c}\mathbf{P} \\
\text { value }\end{array}$ & PFS & $\begin{array}{c}\mathbf{P} \\
\text { value }\end{array}$ \\
\hline Age & $\begin{array}{l}1.027(0.338- \\
3.116)\end{array}$ & 0.9 & $\begin{array}{l}0.643(0.228- \\
1.813)\end{array}$ & 0.4 \\
\hline Histology & $\begin{array}{l}1.018(0.259- \\
3.997)\end{array}$ & 0.8 & $\begin{array}{l}1.006(0.264- \\
3.83)\end{array}$ & 0.92 \\
\hline Grade & $\begin{array}{l}1.039(0.717- \\
1.506)\end{array}$ & 0.39 & $\begin{array}{l}0.977(0.677- \\
1.41)\end{array}$ & 0.80 \\
\hline FIGO stage & $\begin{array}{l}1.009(0.570- \\
1.781)\end{array}$ & 0.55 & $\begin{array}{l}0.99(0.571- \\
1.750)\end{array}$ & 0.99 \\
\hline Tumor size & $\begin{array}{l}2.416(1.166- \\
4.011)\end{array}$ & $0.04^{*}$ & $3.29(1.07-5.24)$ & $0.02^{*}$ \\
\hline PS & $\begin{array}{l}0.990(0.355- \\
2.760)\end{array}$ & 0.58 & $\begin{array}{l}0.924(0.332- \\
2.527)\end{array}$ & 0.53 \\
\hline Cisplatin & $\begin{array}{l}0.960(0.437- \\
2.160)\end{array}$ & 0.19 & $\begin{array}{l}1.16(0.506- \\
2.464)\end{array}$ & 0.17 \\
\hline $\begin{array}{l}\text { Pretreatment } \\
\mathrm{Hb}\end{array}$ & $\begin{array}{l}1.285(1.059- \\
2.953)\end{array}$ & 0.55 & $2.29(1.17-3.95)$ & 0.78 \\
\hline Pelvic node & $\begin{array}{l}0.677(0.276- \\
1.659)\end{array}$ & 0.39 & $\begin{array}{l}1.663(1.07- \\
2.62)\end{array}$ & 0.39 \\
\hline RT duration & $\begin{array}{l}4.893(2.874- \\
7.097)\end{array}$ & $0.01^{*}$ & $\begin{array}{l}4.251(1.055- \\
6.802)\end{array}$ & $0.03^{*}$ \\
\hline
\end{tabular}

(PS-performance status, Hb-haemoglobin, RT-radiotherapy, OS-overall survival, PFS-performance status)

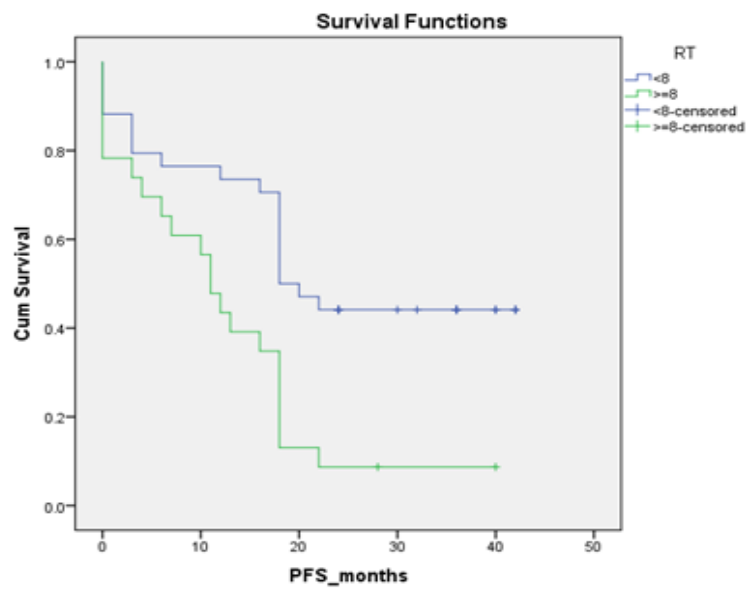

Figure 1: PFS estimate by radiotherapy treatment duration

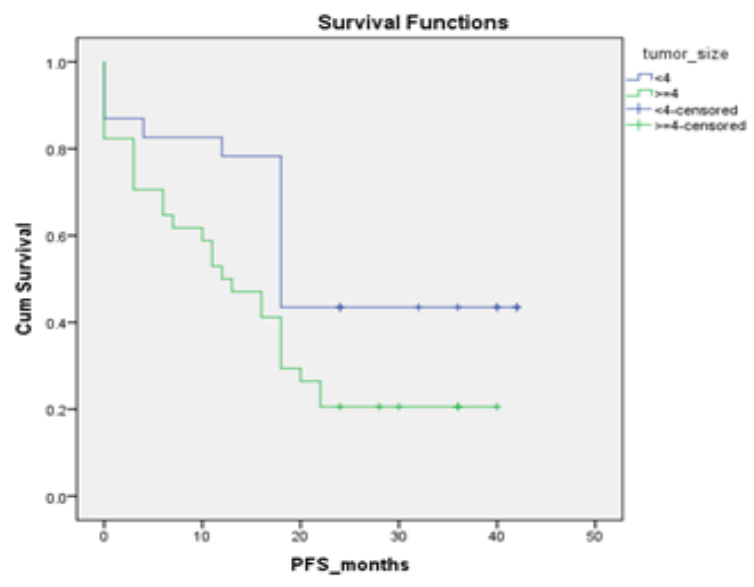

Figure 2: PFS estimate by tumour size 


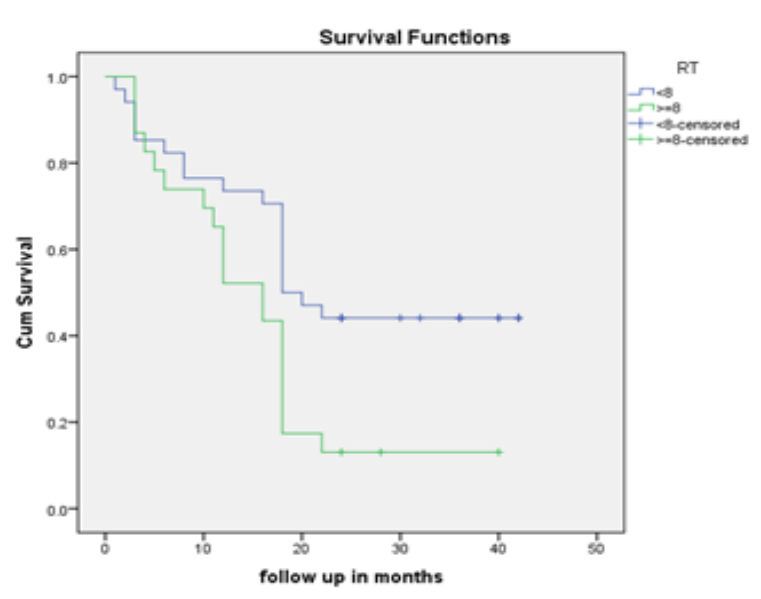

Figure 3: OS estimate by RT duration

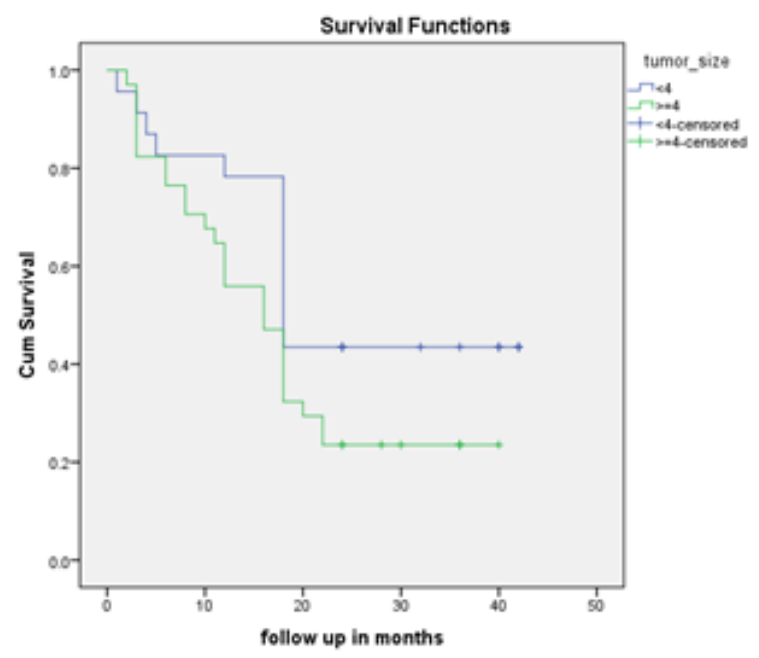

Figure 4: OS estimate based on tumour bulk

\section{Discussion}

Cervical cancer is the most common cancer among women in many developing country. ${ }^{[6]}$ survival. ${ }^{[7]}$ In a study by Torres et al ${ }^{[7]}$ proved the significance of the total dose of cisplatin received by patient was an important predictive factor for increased progression free survival. Our study showed better survival with more number of weekly cisplatin cycles and tended to be correlated with good outcomes in terms of DFS and OS. Many studies proved that adenocarcinoma histology associated with poor survival and in our study couldn't find this difference. The no. of adenocarcinoma cases were less and that may be the reason for not showing the difference of survival. ${ }^{[8]}$

Yamashita et al, ${ }^{[9]}$ reported that pelvic lymph nodes metastases affected OS. Similar results are shown in our study. Previous studies found that FIGO staging and pretreatment hemoglobin were the prognostic factors for survival. ${ }^{[10-13]}$ In our study the difference in survival according to FIGO staging and pretreatment hemoglobin was not significant. The number of patients in each stage in our study is not adequate to find the significance of these parameters. Kodaira et al. ${ }^{[14]}$ demonstrated that maximum tumor diameter of $\geq 5 \mathrm{~cm}$ and lymph node enlargement were independent prognostic factors. Similar results were obtained in our study, in which the bulk of the tumour significantly affected the survival in both univariate and multivariate analysis. Dattoli et al showed that patients $<40$ years old had poorer 5-year survival than patients $>40$ years old. ${ }^{[15]}$ In our study, only seven patients were 40 years old and we could not get significant difference between these two groups.

Studies have shown that there is a strong correlation between duration of total radiation treatment and the survival. ${ }^{[16-19]}$ Prolongation of treatment more than 60 days significantly affects the survival outcome. In our study both OS and PFS were significantly negatively affected by treatment duration ( $>8$ weeks) in univariate and multivariate analysis. It was mainly explained due to accelerated repopulation of the tumour cells after radiation which is documented by Huang et al in a clinical data by using linear quadratic model. ${ }^{[20]}$

This retrospective study had several limitations. First, the small number of patients limited our ability to perform multiple adjustments for potential confounders and the power of our analysis to detect small differences. Second the concurrent chemotherapy used in our study is different from the standard weekly cisplatin $40 \mathrm{mg} / \mathrm{m} 2$ for $5-6$ cycles. In this retrospective study, $80 \%$ of our patients had complete tumour response but only a low proportion (30\%) underwent regular follow-up. The awareness regarding the importance of the follow up and lack of support from the family members might be the reasons of poor follow up in our group of patients. Thus, this study recommended that the family members should be counselled about the importance of the follow-up after treatment.

\section{Conclusion}

Bulky tumour and prolongation of treatment duration were poor prognostic factors for patients with locally advanced cervical cancer. Chemotherapy with a high cumulative dose of cisplatin tended to result in better survival. Measures to improve the follow up after treatment to be identified in our group of patients.

\section{References}

1. Garcia A, Blessing J, Darcy K, et al. Phase II clinical trial of capecitabine in the treatment of advanced, persistent or recurrent squamous cell carcinoma of the cervix with translational research: A gynecologic oncology group study. Gynecol. Oncol., 104: 572-579, 2007.

2. Einhorn N, Trope C, Ridderhein $\mathrm{M}$ et al.: A systemic overview of radiation therapy effects in cervical cancer (cervix uteri).Acta Oncol. 2003;42(5-6):546-56.

3. Rose P., Bundy B., Watkins E., et al.: Concurrent cisplatin-based radiotherapy and chemotherapy improves progression-free survival in advanced cervical cancer: results of a randomized gynecologic oncology group study. New Engl. J. Med., 340: 1144-1153, 1999.

4. Eifel P., Winter K., Morris M., et al.: Pelvic irra-diation with concurrent chemotherapy versus pelvic and para-aortic irradiation for high risk cervical cancer: An update of radiation therapy oncology group trial (RTOG) 90-01. J. Clin. Oncol., 22: 872-880, 2004. 
5. Rose P., Ali S., Watkins E., et al.: Long-term follow-up of a randomized trial comparing concurrent single agent cisplatin, cisplatinbased combination chemotherapy, or hydroxyurea during pelvic irradiation for locally advanced cervical cancer: A gynecologic oncology group study. J. Clin. Oncol., 25: 2804-2810, 2007.

6. Cervical Cancer Action Report Card 2011. Progress in Cervical CancerPrevention. Available rom: http://www.cervicalcanceraction.org/pubs/CCA reportcard low res.pdf.

7. Torres MA, Jhingran A, Thames HD, Levenback CF, Bodurka DC,Ramondetta LM, et al. Comparison of treatment tolerance and outcomes in patients with cervical cancer treated with CCRT in a prospective randomized trial or with standard treatment. IntJ Radiat Oncol Biol Phys 2008;70: 118e

8. Eifel PJ, Burke TW, Morris M, Smith TL. Adenocarcinoma as anindependent risk factor for disease recurrence in patients withstage IB cervical carcinoma. Gynecol Oncol 1995;59:38e44.

9. Yamashita H, Nakagawa K, Tago M, Shiraishi K, Nakamura N,Ohtomo K. Treatment results and prognostic analysis of radical radiotherapy for locally advanced cancer of the uterine cervix.The Br J Radiol 2005;78:821

10. Fyles AW, Milosevic M, Pintilie M, Syed A, Hill RP. Anemia, hypoxia and transfusion in patients with cervix cancer: a review. Radiother Oncol. 2000;57:13-19.

11. Winter WE, 3rd, Maxwell GL, Tian C, Sobel E, Rose GS, Thomas G, et al. Association of hemoglobin level with survival in cervical carcinoma patients treated with concurrent cisplatin and radiotherapy: a Gynecologic Oncology Group Study. Gynecol Oncol. 2004;94:495501.

12. Choi YS, Yi CM, Sin JI, Ye GW, Shin IH, Lee TS. Impact of hemoglobin on survival of cervical carcinoma patients treated with concurrent chemoradiotherapy is dependent on lymph node metastasis findings by magnetic resonance imaging. Int $\mathrm{J}$ Gynecol Cancer.
2006;16:1846-1854.

13. Kuroda Y, Murakami N, Morota M, Sekii S, Takahashi K, Inaba K, et al. Impact of concurrent chemotherapy on definitive radiotherapy for women with FIGO IIIb cervical cancer. J Radiat Res. 2012;53:588593.

14. Kodaira T, Fuwa N, Kamata M, Furutani K, Kuzuya K, Ogawa K, et al. Clinical assessment by MRI for patients with stage II cervical carcinoma treated by radiation alone in multicenter analysis: are all patients with stage II disease suitable candidates for chemoradiotherapy? Int J Radiat Oncol Biol Phys. 2002;52:627-636.

15. Dattoli MJ, Gretz III HF, Beller U, Lerch IA, Demopoulos RI, Beckman EM, et al. Analysis of multiple prognostic factors in patients with stage IB cervical cancer: age as a major determinant. Int J Radiat Oncol Biol Phys 1989;17:41e7.

16. Fyles A, Keane TJ, Barton M, Simm J (1992) The effect of treatment duration in the local control of cervix cancer. Radiother Oncol 25: 273279.

17. Girinsky T, Rey A, Roche B, Haie C, Gerbaulet A, et al. (1993) Overall treatment time in advanced cervical carcinomas: a critical parameter in treatmentoutcome. Int J Radiat Oncol Biol Phys 27: 1051-1056.

18. Petereit DG, Sarkaria JN, Chappell R, Fowler JF, Hartmann TJ, et al. (1995).The adverse effect of treatment prolongation in cervical carcinoma. Int J Radiat Oncol Biol Phys 32: 1301-1307.

19. Chen SW, Liang JA, Yang SN, Ko HL, Lin FJ (2003) The adverse effect of treatment prolongation in cervical cancer by high-dose-rate intracavitary brachytherapy. Radiother Oncol 67: 69-76.

20. Huang Z, Mayr NA, Gao M, Lo SS, Wang JZ, et al. (2012) Onset time of tumorrepopulation for cervical cancer: first evidence from clinical data. Int J RadiatOncol Biol Phys 84: 478-484.

Copyright: (C) the author(s), 2019. It is an open-access article distributed under the terms of the Creative Commons Attribution License (CC BY 4.0), which permits authors to retain ownership of the copyright for their content, and allow anyone to download, reuse, reprint, modify, distribute and/or copy the content as long as the original authors and source are cited.

How to cite this article: Jeeva S, Ramanan VA, Sowmiya KR, Balasubramaniam P, Vidya, Chandralekha. The Prognostic Factors for Locally Advancedcervical Cancer Patients Treated by Cisplatin Based Concurrent Chemoradiotherpy- A Retrospective Study. Asian J. Med. Res. 2019;8(1):MC05-MC09.

DOI: dx.doi.org/10.21276/ajmr.2019.8.1.MC2 